\title{
Clustering consumers who engage in boycotting: New insights into the relationship between political consumerism and institutional trust
}

\author{
Nuno Tiago Baptista ${ }^{1}$ - Ricardo Gouveia Rodrigues ${ }^{1}$
}

Received: 11 June 2017 / Accepted: 10 January 2018

(C) Springer-Verlag GmbH Germany, part of Springer Nature 2018

\begin{abstract}
This study proposes a segmentation model for European consumers engaging in boycotting and examines each segment's level of trust in public institutions. Using data from the European Social Survey (ESS), measures of generalized trust, social participation, interest in politics, human values and demographics were used as segmentation variables in a two-cluster solution. The two clusters, labeled conservative majority and active idealists, revealed significant differences in their levels of institutional trust in 10 of the 21 countries analyzed. These findings highlight the potential heterogeneity of consumers engaging in boycotting and offer an explanation for extant contrasting findings regarding the relationship between institutional trust and political consumerism.
\end{abstract}

Keywords Boycotting · Institutional trust $\cdot$ Segmentation $\cdot$ Political consumerism

\section{Introduction}

Contrary to the tendency verified in traditional political participation activities such as voting, the last decade is characterized by the spread of alternative forms of political activity (Acik 2013; Ferrer-Fons and Fraile 2014), a development that has been related with globalization and the widespread use of information and communication technologies, which have triggered lifestyle politics and a shared sense of moral obligation (Koos 2012; Acik 2013).

Political consumerism is understood as a form of political activity beyond the traditional manifestations, where consumers use their purchasing power to attain

\section{Nuno Tiago Baptista}

leitao.baptista@ubi.pt

1 Abrideias, Faculdade de Ciências Sociais e Humanas, Universidade da Beira Interior Estrada do Sineiro, s/n, 6200-209 Covilhã, Portugal 
political, societal, environmental or ethical objectives (Koos 2012). The most common manifestations of political consumerism include abstention from buying (boycotting) and intentional buying (buycotting) of products or services (Ferrer-Fons and Fraile 2014).

In most studies of political consumerism, boycotters and buycotters are treated indifferently, and yet there is some empirical evidence that the characteristics and motivations of political consumers may vary significantly (Neilson 2010). As such, these differences stress the need to research separately each type of political consumerism manifestation. This research focus on a specific form of political consumerism that is consumer boycotts. The study of consumer boycotts is relevant for marketing because they express consumers' discontent, and should be countered by targeted organizations before they risk viral propagation (Albrecht et al. 2013).

Institutional trust, understood as trust in national organizations has been identified as a key indicator of the quality of government-citizen relationships and to be related with political consumerism (Neilson 2010; Koos 2012; Aish et al. 2013). The link between institutional trust and political consumerism is not perfectly defined since existing research presents opposing results. While some authors demonstrated that political consumerism is positively associated with institutional trust (e.g. Andersen and Tobiasen 2004; Stolle and Hooghe 2004), others indicate that distrust motivates political consumerism (e.g. Hoffmann and Müller 2009; Koos 2012; Aish et al. 2013).

By clustering European boycotters and examining each segment's level of trust in public institutions, this study advances a possible explanation to the supra mentioned contrasting findings of previous literature and addresses the following research problem: How to explain the contrasting findings of previous research regarding the relationship between political consumerism and institutional trust?

This study posits that consumers who pledge boycott participation are a heterogeneous group and that the reason for the inconsistent findings is that boycotters may exhibit differentiated levels of institutional trust, depending on their characteristics and also the type of institutional organization.

Responding to De Barcellos' et al. (2014) call for research that using cluster analysis could characterize political consumers, in order to improve the understanding of their profile, the objectives of this study are to present a possible segmentation model for European boycotters and to examine each segment's level of institutional trust.

\section{Theoretical context}

\subsection{Consumer boycotting}

The concept of political consumerism is traditionally employed in reference to the boycott or buycott of products or services undertaken by consumers (Yates 2011; Koos 2012; Wicks et al. 2013; Ferrer-Fons and Fraile 2014). Ferrer-Fons and Fraile (2014, p. 467) define political consumption as "the intentional buying or abstention from buying (boycotting) specific products for political, ethical, or ecological reasons." Political consumerism has been characterized as an example of new politics (Yates 2011) and its distinctive characteristic, when compared with other forms of unconventional political participation, is that market transactions are used as a way of protesting or rewarding desirable institutional behaviors (Koos 2012). 
Although political consumerism is mostly identified with boycotting and buycotting, the relationship between political consumerism and other forms of unconventional political participation has not been consensually defined. In fact, besides boycotting and buycotting, some authors include in political consumerism other actions such as signing petitions (Acik 2013), culture jamming, voluntary simplicity, or the choice to live in an eco-village (Bossy 2014).

In addition, the literature differs in the nomenclature used to refer to boycotting and buycotting actions, using alternately the denominations of political consumerism or consumption, ethical consumption and critical consumption (Yates 2011). According to Yates (2011) the critical consumption denomination has the advantage of expressing substantive neutrality over the motives for boycotting or buycotting and still retaining the emphasis on the deliberate act of consumption agency from the part of the consumer. Despite the validity of the argumentation presented by Yates, in this research we adopted the term political consumerism because the focus of this study is on the relationship between boycotting and trust in public institutions, implying that the emphasis is more on the political side of critical consumption.

Boycotting, also known as negative consumerism (Ferrer-Fons and Fraile 2014), refers to the abstention from buying a product or service on the grounds of political, ethical or environmental motivations (Yates 2011). Friedman (1985, p. 97) defines consumer boycotts as "an attempt by one or more parties to achieve certain objectives by urging individual consumers to refrain from making selected purchases in the marketplace". Boycotts have been considered an egregious behavior from consumers that can both impact the wellbeing of the boycotter (due to consumer's dependence, preference, or loyalty to the boycotted product, as well as the unavailability of affordable substitutes) and cause harm to the targets of boycotting, thus consumers participating in boycotts express severe dissatisfaction with the target of these actions and a desire for punitive action (Braunsberger and Buckler 2011).

European countries constitute a challenging case study to analyze consumer boycotting because of their diversity. When compared to Northern European Countries, Southern and Eastern European countries were found to have markedly lower levels of critical consumption (Yates 2011; Acik 2013). Ferrer-Fons and Fraile (2014) advert to the existence of factors at the macro-level that influence participation and consumption patterns, including: i) the availability and extension of the distribution points of the supply side; ii) cultural patterns of consumption; iii) post-materialist values, and environmental concerns in each country. According to these authors in some European countries, such as Germany or the Netherlands, vegetarianism and "green" consumption are deeply rooted in broad sectors of society. These differences recommend an approach to the study of consumers boycotting in Europe that is sensitive to the social, cultural and structural contexts of countries.

Considering Zhang's (2015) assertion, that political consumerism results from the impacts of both individual characteristics and societal determinants, this study follows Hong's et al. (2012) methodology, by assuming that a combination of objective variables (demographics) with inferred variables (social participation, interest in politics, generalized trust and human values) will generate a comprehensive segmentation model to study European boycotters. Next we present the theoretical foundation for the selected variables. 


\subsection{Demographics}

The socio-economic stratification of political consumerism has been empirically observed in several studies (Yates 2011; Hong et al. 2012; Koos 2012; Acik 2013). In contrast to men's traditional dominance of participation forms, there is strong theoretical and empirical support that women shop politically more frequently than men, the most plausible explanation being related with traditional female roles in provisioning (Yates 2011; Koos 2012; Acik 2013).

Researchers have also observed a curvilinear relationship between age and political consumerism, meaning that very young and old people consume less politically than middle-aged consumers, this relationship has been attributed to life-cycle and generational effects (Koos 2012; Acik 2013).

Education has also been positively associated with political consumerism. Yate's (2011) research found that the more years of full-time education, the greater the likelihood of consumers engaging in political consumerism. On the other hand, several studies postulate that monetary resources can constitute a budget restriction for political consumerism (Yates 2011; Hong et al. 2012). The socio-economic status (SES) model, developed by Verba and Nie (1972), offers a relevant explanation for this relationship, by establishing a link between education, socio-economic status, and political participation. According to the SES model, high levels of formal education provide individuals with the knowledge and the conceptual abilities to understand complex political issues, thus enabling them to take part in politics. Individuals from higher SES are also more likely to have the resources (skills, money) and interest to be involved (Acik 2013).

\subsection{Generalized trust}

Generalized trust has been defined as "the level of faith people have in those around them" (Schoene 2016, p.6). According to Neilson (2010), generalized trust may influence political consumerism in two distinctive ways. First, people who trust information about political consumerism should be more apt to act upon this information. Second, generalized trust can manifest itself in a belief that those proposing political consumerism acts have good intentions. On the other hand, trusting that others will also boycott might lead a political consumer to feel part of a larger, collective effort.

Social movements, such as the ones that support boycotting, need people working together to be successful, so generalized trust can act as an important structural resource (Schoene 2016). Generalized trust in others can be considered a prerequisite for collective behavior since trust helps to build collective identities that form the basis of social movements (Schoene 2016).

Several studies indicate a positive relationship between generalized trust and boycotting. Schoene's (2016) research indicates that generalized trust increases the probability of wearing a badge, signing a petition, boycotting a product and protesting. Koos (2012) empirical study also found that individuals' generalized trust increases the likelihood of engagement in both forms of political consumption, boycotting and buycotting. 


\subsection{Social participation}

Social participation refers to individual participation in diverse social organizations, such as non-profit organization or political parties (Hong et al. 2012). Political consumption is generally understood as a form of self-expressive participation with a more individualized and advocatory format, when compared to traditional political participation (Baek 2010). However, some authors indicate that those who engage in political consumption practices are more likely to also engage in political activism (Willis and Schor 2012; De Barcellos et al. 2014).

Political consumerism has been positively linked with involvement in voluntary associations (Neilson 2010) and Gotlieb and Wells (2012) found that political consumerism predicts political participation or efforts to affect the electoral process, government action, or public policy. By including social participation as a variable in the segmentation of boycotters, this research incorporates individuals' connectedness to society, which, in turn, has been associated with trust in government institutions (Hong et al. 2012).

\subsection{Interest in politics}

Political interest signals an individual's concern for community governance and has been acknowledged as a potential indicator of the willingness to engage in political activism (Koos 2012; Wicks et al. 2013).

Neilson and Paxton's (2010) research indicates that individuals who are more interested in politics or who have more definite political opinions are more likely to politically consume. In addition, Koos' (2012) research found that interest in politics, as well as a strong sense of political efficacy, had a significant positive effect on both boycotting and positive buying.

\subsection{Human values}

Boycott participation is a complex expression of each participant's individuality (Braunsberger and Buckler 2011). Human values may explain political attitudes, attitudes toward societal groups or social and economic policies and can influence opinions and behavior (Davidov 2010).

The Schwartz Value Scale (Schwartz 1992) is used on the ESS to measure human values. Schwartz (1994, p.21) defines values as "desirable, transsituational goals, varying in importance, that serve as guiding principles in people's lives". In his theory Schwartz proposed 10 basic values: i) power (valuing social status, control, dominance); ii) achievement (valuing success and competence); iii) hedonism (valuing selfgratification and enjoyment); iv) stimulation (valuing novelty and new challenges); v) self-direction (valuing independent activity and creativity); vi) universalism (valuing equality and principled justice); vii) benevolence (valuing welfare of significant others); viii) tradition (valuing observance of historical traditions and customs); ix) conformity (valuing restraint, politeness and impulse control) and; $\mathrm{x}$ ) security (valuing safety and order in society and relationships).

In addition, Schwartz's $(1992,1994)$ theory suggests a structural relationship between the 10 human values, implying that they can be group in four "higher order 
values": i) conservative values, which include tradition conformity and security; ii) openness to change values, including stimulation and self-direction and hedonism; iii) self-transcendent values, including universalism and benevolence and; iv) selfenhancement values, including power, achievement and hedonism. This set of ten values and four higher order values was found to be factorially invariant across at least 20 cultures (Schwartz et al. 2001 cited in Robinson 2013, p.12).

\section{Research questions and hypotheses}

Having described the theoretical foundations for the selection of each of the segmentation variables, we now specify the first research question.

\subsection{Research question 1}

RQ1: How can consumer boycotters be segmented into homogenous groups of publics based on demographics, their levels of generalized trust, social participation, interest in politics and human values, and what are the main characteristics of each segment of boycotters identified?

The first research question will be answered by identifying a segmentation model of consumers engaging in boycotting in the selected countries included in the ESS (Austria, Belgium, Switzerland, Czech Republic, Germany, Denmark, Estonia, Spain, Finland, France, United Kingdom, Hungary, Ireland, Israel, Lithuania, Netherlands, Norway, Poland, Portugal, Sweden and Slovenia). Linked with the first research question, we present the following hypothesis:

H1: Consumers engaging in boycotting are not homogeneous in terms of demographics, their levels of generalized trust, social participation, interest in politics and human values.

Institutional trust in public organizations has been identified as an important indicator of organization-public relationships' quality and to be strongly linked to individuals' attitudinal and behavioral responses (Hong et al. 2012). Ki and Hon (2007, p. 422) define institutional trust as "a belief by publics that an organization is reliable, honest, and stands by its words as well as accomplishes its promised obligations". There is evidence that trust in institutions influences political consumerism, however the direction of this influence is not clear. Some authors concluded that political consumerism is positively associated with institutional trust (Andersen and Tobiasen 2004; Stolle and Hooghe 2004) suggesting that those who trust believe that their actions will be supported by political bodies and are therefore more motivated to act by engaging in political consumerism (Neilson 2010). Others studies (Hoffmann and Müller 2009; Koos 2012; Aish et al. 2013) indicate that distrust motivates political consumerism. Stolle et al. (2005) suggest that those who do not trust institutions feel the need to rely on their own actions engaging in more individualized political actions such as political consumerism. 
Neilson (2010) pointed differences between boycotters and buycotters as the reason for the previously mentioned inconsistent findings. This author found that those who are more trusting of institutions are significantly more likely to buycott and those who are less trusting of institutions are significantly more likely to boycott. Despite the solid explanation offered by Neilson's (2010) study, there is also the possibility that each typology of boycotter may exhibit differentiated levels of institutional trust, a hypothesis that, to the best of our knowledge, has not been tested before.

\subsection{Research question 2}

The second part of this research analyzes the level of trust in government institutions among the previously identified segments, and attempts to answer the following research question:

RQ2: How do the identified segments of consumers engaging in boycotting differ in relation to trust in public institutions?

Considering the opposing results in the literature in terms of the direction of the relationship between political consumerism and institutional trust, we intend to test the following hypothesis, which implies that the inconsistent findings of previous studies may be related with the heterogeneity of political consumers in general and boycotters in particular:

H2: Different segments of boycotters differ in their level of trust in public institutions.

\section{Methodology}

\subsection{Data sources}

This study uses data from the seventh round (2014) of the ESS. This survey measures the attitudes, beliefs and behavior patterns of diverse European populations (and Israel) and was a 2005 recipient of the prestigious Descartes Prize for Research and Science Communication and awarded European Research Infrastructure Consortium (ERIC) status in 2013.

The ESS sampling was designed to obtain equal sampling strategies in all participating countries. Samples were all derived by following similar principles of stringent probability and representativeness (Hong et al. 2012). In each wave, the ESS is based on face-to-face interviews within a predetermined sampling frame to collect data on attitudes, beliefs and behaviors across the diverse populations.

For the purpose of this research, the most recent available wave is used. Considering the focus of this research, the lack of large-scale comparative data sets on boycotting and the validity of the measures in the ESS, this survey is considered to be well suited to operationalize the concepts of interest in this research. 


\subsection{Measurement}

\subsubsection{Boycott variable}

The classification of individuals as boycotters is based on a dichotomous variable (yes or no) derived from the following question in the ESS: "There are different ways of trying to improve things in [country] or help prevent things from going wrong. During the last 12 months, have you done any of the following?... boycotted certain products". According to Koos (2012), this question has proved to be an efficient and valid measure of political consumerism.

\subsubsection{Demographics}

From the ESS we operationalized variables concerning gender, age, income, and education. Gender is a simple dichotomous variable and age was computed based on the year of birth of each respondent. To measure education levels we followed Schoene's (2016) approach and used a variable that indicates the total years of fulltime education completed.

Income was measured with a question regarding respondent's household total net income, from all type of sources. To achieve cross-country comparison, the categories in the variable are national and based on deciles of the actual household income range in the given country. The variable has a 10point scale, ranging from 1 , corresponding to the first decile, to 10 , corresponding to the 10 th decile. To facilitate comparison, we opted to reversecode the item scores so that higher values on the items would reflect higher incomes.

\subsubsection{Generalized trust}

Following previous literature (Neilson 2010) generalized trust was measured based on three questions on the ESS, including: i) "Generally speaking, would you say that most people can be trusted, or that you can't be too careful in dealing with people?"; ii) "Do you think that most people would try to take advantage of you if they got the chance, or would they try to be fair?" and; iii) "Would you say that most of the time people try to be helpful or are mostly looking out for themselves?".

Responses were made on an 11-point scale, and item scores were averaged to create a composite index $(\alpha=.75)$. A factor analysis using the principle component solution with a varimax rotation method confirmed the validity of the construct, as conceptually assumed, with eigenvalues greater than 1.0, accounting for approximately $67 \%$ of the variance. Examination of the data revealed a Kaiser-Meyer-Olkin measure of sampling adequacy of .68, with a significant Bartlett's test of sphericity $(p=0.00)$. These measures indicate that the data is suitable for factoring. The items in each dimension appear to have adequate factor loadings (above 0.5) indicating conceptual consistency within the dimension. 


\subsubsection{Social participation}

Social participation is a latent construct that cannot be observed or measured directly. However, a pair of questions that are asked in the ESS about involvement in political parties, action groups and other organizations enables us to capture social participation. To evaluate social participation, we used the following two questions, separately: "There are different ways of trying to improve things in [country] or help prevent things from going wrong. During the last 12 months, have you done any of the following? i) worked in a political party or action group? ii) worked in another organization or association?". Respondents were asked to give a yes or no answer.

\subsubsection{Interest in politics}

To measure interest in politics, respondents were asked to rate how interested they were in politics on a 4-point scale ranging from 1 (very interested) to 4 (not at all interested). To facilitate the interpretation, we opted to reverse-code the item scores so that higher values on the items would reflect higher interest in politics.

\subsubsection{Human values}

Human values are evaluated on the ESS based on Schwartz's (1992) original 40-item portrait values questionnaire. However, Schwartz shortened this battery of questions to allow its inclusion in the ESS (Davidov 2010). The ESS includes 21 questions to measure the 10 human values.

The questions describe a fictitious individual, and the respondent is asked to rate the extent to which this person is, or is not, like him or her, in a scale of 1 (Very much like me) to 6 (Not like me at all). To facilitate the interpretation, the item scores for each question were reverse-coded. The specific questions can be consulted on the ESS web site.

Running a Principal Component Analysis, using the principle component solution with a varimax rotation, we obtained 4 factors that explain $46 \%$ of all the variance. Considering that the obtained factors match the higher end values proposed by Schwartz (1994) we consider the solution to be suitable and named the factors according to the labels proposed by Schwartz (1994). The Kaiser-Meyer-Olkin measure of sampling adequacy was .82 , with a significant Bartlett's test of sphericity ( $p=$ 0.00). The items in each dimension had adequate factor loadings (above 0.5).

The item scores were averaged to create an index for each dimension: conservation $(\alpha=.70)$, openness to change $(\alpha=.70)$, self-enhancement $(\alpha=.72)$ and self-transcendence $(\alpha=.67)$.

\subsubsection{Institutional trust}

Based on previous literature (Hong et al. 2012), institutional trust was measured for several public institutions based on 5 questions in the ESS. Respondents were asked to rate how much they personally trust each of the following institutions: their country's parliament, their country's legal system, the police, political parties and the United Nations. Responses were made on an 11-point scale, ranging from 0 (No trust) to 10 (Complete trust). 


\section{Results}

\subsection{Descriptive statistics}

An initial comparison of the number of boycotters in the studied countries highlights the disparity in the proportion of citizens that have carried out boycotting. Table 1, bellow, indicates the percentages of citizens that have engage in boycotting in the last 12 months, after weighting for the study design, non-response bias and population size, according to the methodology suggested by the ESS (2014).

The data shows that under a fourth of the total sample have engaged in boycotting. It is also possible to observe a difference between bloc countries. Northern-western European countries are markedly characterized by higher levels of boycotting and former eastern bloc countries present the lowest levels, a difference that has also been

Table 1 Level of citizen boycotting, 2014 (percentages)

\begin{tabular}{|c|c|c|c|}
\hline $\begin{array}{l}\text { Boycotted certain products } \\
\text { last } 12 \text { months }\end{array}$ & Yes & No & $\mathrm{N}$ \\
\hline Southern Europe & 16.3 & 83.7 & 3179 \\
\hline Spain & 18.0 & 82.0 & 1921 \\
\hline Portugal & 6.7 & 93.3 & 1258 \\
\hline Northern Europe & 26.2 & 73.8 & 11,426 \\
\hline United Kingdom & 23.2 & 76.8 & 2264 \\
\hline Denmark & 26.5 & 73.5 & 1499 \\
\hline Finland & 36.4 & 63.6 & 2083 \\
\hline Ireland & 14.5 & 85.5 & 2373 \\
\hline Norway & 24.7 & 75.3 & 1431 \\
\hline Sweden & 46.4 & 53.6 & 1776 \\
\hline Western Europe & 30.2 & 69.8 & 11,933 \\
\hline Austria & 25.9 & 74.1 & 1773 \\
\hline Germany & 33.6 & 66.4 & 3041 \\
\hline Belgium & 14.3 & 85.7 & 1765 \\
\hline Netherlands & 14.4 & 85.6 & 1916 \\
\hline France & 33.5 & 66.5 & 1910 \\
\hline Switzerland & 28.9 & 71.1 & 1528 \\
\hline Former Eastern bloc & 5.9 & 94.1 & 10,901 \\
\hline Hungary & 2.8 & 97.2 & 1687 \\
\hline Poland & 5.9 & 94.1 & 1606 \\
\hline Estonia & 8.3 & 91.7 & 2036 \\
\hline Lithuania & 3.8 & 96.2 & 2232 \\
\hline Slovenia & 6.9 & 93.1 & 1214 \\
\hline Czech Republic & 9.2 & 90.8 & 2126 \\
\hline Others & 11.1 & 88.9 & 2562 \\
\hline Israel & 11.1 & 88.9 & 2562 \\
\hline Total & 23.1 & 76.9 & 40,001 \\
\hline
\end{tabular}


highlighted in previous literature (Yates 2011; Hong et al. 2012) and attributed to cultural, political regime and welfare system differences.

Although the original dataset included 7797 cases of boycotters, we opted for deleting all cases with missing values resulting in 5981 cases for data analysis. This same procedure has been adopted in similar studies (Hong et al. 2012) and aims to improve rigor in the statistical tests. Table 2 shows the remaining number of boycotters and the respective means and standard deviations of the variables age and years of fulltime education completed and Table 3 puts in evidence the mode and quartiles of the variables generalized trust, household income, interest in politics and the variables related with human values (conservation, openness to change, self-transcendence and self-enhancement).

Based on Tables 2 and 3, we can generally characterize the sample of boycotters as being predominantly middle aged, with high levels of education, middle level of income, exhibiting generalized trust, ranking higher in conservation and interested in politics. We can further add that among the boycotters sampled 53\% (3165 individuals) are female, $9 \%$ (544 individuals) worked in political parties or action groups in the last 12 months and that $37 \%$ (2219 individuals) worked in other organizations during the same time period. Analyzing the database before eliminating the missing cases we found these descriptive statistics to be comparable as the ones obtained in the full dataset. This general characterization of the sample may hide meaningful differences among types of boycotters, hence the importance of segmenting this type of political consumers.

\subsubsection{Cluster analysis for research question 1}

The first research question questions how consumer boycotters could possibly be segmented into homogenous groups based on their levels of generalized trust, social participation, interest in politics, human values and demographics and what are the main characteristics of each segment identified. For this purpose, a two-step cluster analysis procedure was conducted in order to categorize the sampled respondents.

The algorithm employed by a two-step cluster analysis has several desirable features, including the capability of handling of categorical and continuous variables and allowing the analysis of large data files (IBM 2011). Using SPSS version 24, the suggested solution obtained for the all sample was a two-cluster solution. The loglikelihood distance measure was used to calculate distances between the clusters and the optimal number of clusters was identified using Schwarz's Bayesian Criterion. The individual recommended solution for the analyzed countries varied between the maximum of 10 clusters (Sweden) and the minimum of 1 cluster (Czech Republic,

Table 2 Descriptive statistics (scale variables)

\begin{tabular}{llllll}
\hline & N & Minimum & Maximum & Mean & Std. deviation \\
\hline Age of respondent & 5981 & 15 & 94 & 49.16 & 16.14 \\
Years of full-time education completed & 5981 & 0 & 50 & 14.49 & 3.99 \\
Valid N (listwise) & 5981 & & & & \\
\hline
\end{tabular}


Table 3 Descriptive statistics (ordinal variables)

\begin{tabular}{|c|c|c|c|c|c|c|c|c|}
\hline & & v1 & $\mathrm{v} 2$ & v3 & $\mathrm{v} 4$ & v5 & v6 & v7 \\
\hline \multirow[t]{2}{*}{$\mathrm{N}$} & Valid & 5981 & 5981 & 5981 & 5981 & 5981 & 5981 & 5981 \\
\hline & Missing & 0 & 0 & 0 & 0 & 0 & 0 & 0 \\
\hline Mode & & 6.67 & 4.17 & 5.00 & 2.75 & 4.00 & 3.00 & 1.00 \\
\hline Minimum & &, 00 & 1.17 & 1.00 & 1.00 & 1.00 & 1.00 & 1.00 \\
\hline Maximum & & 10.00 & 6.00 & 6.00 & 6.00 & 6.00 & 4.00 & 10.00 \\
\hline \multirow[t]{3}{*}{ Percentiles } & 25 & 5.00 & 3.50 & 4.71 & 2.75 & 3.25 & 2.00 & 3.00 \\
\hline & 50 & 6.33 & 4.17 & 5.14 & 3.25 & 4.00 & 3.00 & 5.00 \\
\hline & 75 & 7.00 & 4.67 & 5.43 & 4.00 & 4.50 & 3.00 & 7.00 \\
\hline
\end{tabular}

$\mathrm{v} 1$ = generalized trust; v2 = conservation; v3 = self-transcendence; v4 = self-enhancement; v5= openness to change; $v 6=$ interest in politics; $\mathrm{v} 7=$ household's total net income

Hungary, Lithuania, Poland and Portugal). Because a visual inspection is considered a common approach to determining the specific number of clusters in cluster analysis (Hong et al. 2012), the SPSS recommended two-cluster solution was adopted for all the sampled countries to allow comparison after examining some descriptive statistics of the segmentation variables. In order of predictor importance, the relative contribution of the variables to the cluster solution, from greatest to least, was as follows: worked in another organization, worked in political party, interest in politics, generalized trust, education, self-transcendence, conservation, income, openness to change and gender. The variables age and self-enhancement had no effect on cluster formation. These results confirmed how social activism, whether in political parties or in other organizations, markedly distinguishes differentiated types of boycotters (predictor importance equal to 1 ).

The clustering solution was validated by following the methodology suggested by Norusis (2008). First, model fit was evaluated by the silhouette coefficient, which is a measure of cohesion and separation of clusters. The obtained value of 0.3 , is considered as "fair" and above the required level of 0.0 , suggesting validity of the within- and between-cluster distances (Norusis 2008). Second, Pearson's chi-squared tests and independent samples T-tests for the categorical and continuous variables respectively, confirmed that the clusters varied significantly across the 12 segmentation variables, with the exception of the variables self-enhancement $\left(\chi^{2}(20)=26.29 ; \rho=0.157\right)$ and age $(\mathrm{t}(5979)=-1.81 ; \rho=0.071)$. These results are unsurprising considering the predictors' importance levels previously reported. Finally, the cluster solution was assessed by splitting the dataset into random halves and running the same statistical procedures. The obtained results for each halved sample were similar in terms of the number and characteristics of the clusters, silhouette measures of cohesion and separation and predictors importance.

The first cluster included the majority of the respondents both in the all sample (62\%; 3706 individuals) and in the large majority of the countries analyzed, exceptions made to Finland (48\%, 333 individuals) and Netherlands (49\%, 116 individuals). The largest percentages of respondents in this first cluster were found in Israel $(86 \% ; 119$ individuals) and Hungary (85\%, 28 individuals). This cluster can be described as 
having higher income, but less years of full-time education, when compared with the other segment. They are less likely to belong to political parties and other organizations and have less interest in politics. They also reveal less generalized trust in others. In terms of human values, the most prominent dimension is conservatism, meaning that the individuals of this segment favor values such as conformity, tradition and security. Considering these characteristics we opted to label this cluster as the "conservative majority".

The second cluster is composed by 2275 individuals. The elements of this segment are characterized by higher levels of social participation, being more likely to belong to political parties, activist groups and other type of organizations. They are very educated, interested in politics and have comparable higher levels of generalized trust, meaning that they tend to trust more in other people. The most salient human value is self-transcendence, scoring high in universalism and benevolence. They also rank higher in openness to change, when compared with the other cluster. We opted to name this cluster as the "active idealists".

The two segments do not show considerable differences in terms of age and self-enhancement values (medium age in both clusters is around 50 years old, with standard deviations in both segments of 16 years). We also found that females are prevalent in both clusters (54\% in the segment conservative majority and $51 \%$ in the segment active idealist). Table 4 synthetizes the main characteristics of both segments.

\subsubsection{Mann-Whitney tests for research question 2}

After characterizing the segments, nonparametric Mann-Whitney tests were conducted to explore the differences between the two clusters (segments of boycotters) regarding trust in several public institutions. The boycott segments served as the independent variable and the five institutional trust variables as dependent variables.

The option for Mann-Whitney tests, in alternative to independent samples T-test, was based on the failure of the assumption of normally of the variables related with institutional trust in each segment of boycotters and the verification that the distributions were skewed, precluding the application of the central limit theorem. The values for asymmetry (division of skewness values by their respective standard errors) were outside of the recommended range of $[-2 ; 2]$ (George and Mallery 2010).

Table 4 Characteristics of the boycotters segments

\begin{tabular}{lll}
\hline & Conservative majority & Active idealists \\
\hline Factors & & \\
Social behaviour & $\bullet$ Low social participation & $\bullet$ High social participation \\
& $\bullet$ Low Interest in politics & $\bullet$ High Interest in politics \\
Demograhics & $\bullet$ Higher income & $\bullet$ Lower Income \\
& $\bullet$ Lower education & $\bullet$ Higher education \\
Human values & $\bullet$ Conservative & $\bullet$ Self-transcendence/openness to change \\
\hline
\end{tabular}


Table 5 Significant differences in institutional trust (values of Mann-Whitney tests)

\begin{tabular}{|c|c|c|c|c|c|c|}
\hline Country & & Segments & $\mathrm{N}$ & Mean rank & $\mathrm{U}$ & $\rho$ \\
\hline \multirow[t]{2}{*}{ Austria } & \multirow[t]{2}{*}{ Trust in political parties } & Conservative Majority & 196 & 140.55 & \multirow[t]{2}{*}{8241.0} & \multirow[t]{2}{*}{0.008} \\
\hline & & Active Idealist & 103 & 167.99 & & \\
\hline \multirow[t]{8}{*}{ Belgium } & \multirow[t]{2}{*}{ Trust in country's parliament } & Conservative Majority & 163 & 111.70 & \multirow[t]{2}{*}{4841.0} & \multirow[t]{2}{*}{0.004} \\
\hline & & Active Idealist & 77 & 139.13 & & \\
\hline & \multirow[t]{2}{*}{ Trust in the legal system } & Conservative Majority & 163 & 110.37 & \multirow[t]{2}{*}{4623.5} & \multirow[t]{2}{*}{0.001} \\
\hline & & Active Idealist & 77 & 141.95 & & \\
\hline & \multirow[t]{2}{*}{ Trust in the police } & Conservative Majority & 163 & 111.35 & \multirow[t]{2}{*}{4784.0} & \multirow[t]{2}{*}{0.003} \\
\hline & & Active Idealist & 77 & 139.87 & & \\
\hline & \multirow[t]{2}{*}{ Trust in political parties } & Conservative Majority & 163 & 113.68 & \multirow[t]{2}{*}{5164.0} & \multirow[t]{2}{*}{0.025} \\
\hline & & Active Idealist & 77 & 134.94 & & \\
\hline \multirow[t]{2}{*}{ Germany } & \multirow[t]{2}{*}{ Trust in country's parliament } & Conservative Majority & 515 & 423.21 & \multirow[t]{2}{*}{$85,082.0$} & \multirow[t]{2}{*}{0.005} \\
\hline & & Active Idealist & 371 & 471.67 & & \\
\hline \multirow[t]{2}{*}{ Denmark } & \multirow[t]{2}{*}{ Trust in country's parliament } & Conservative Majority & 188 & 157.36 & \multirow[t]{2}{*}{$11,818.0$} & \multirow[t]{2}{*}{0.010} \\
\hline & & Active Idealist & 150 & 184.71 & & \\
\hline Finland & Trust in country's parliament & Conservative Majority & 333 & 322.62 & $51,820.5$ & 0.002 \\
\hline & & Active Idealist & 360 & 369.55 & & \\
\hline & Trust in political parties & Conservative Majority & 333 & 330.05 & $54,296.5$ & 0.031 \\
\hline & & Active Idealist & 360 & 362.68 & & \\
\hline France & Trust in country's parliament & Conservative Majority & 425 & 286.49 & $31,234.5$ & 0.005 \\
\hline & & Active Idealist & 172 & 329.90 & & \\
\hline & Trust in the legal system & Conservative Majority & 425 & 287.18 & $31,525.0$ & 0.008 \\
\hline & & Active Idealist & 172 & 328.22 & & \\
\hline & Trust in political parties & Conservative Majority & 425 & 288.96 & $32,285.0$ & 0.024 \\
\hline & & Active Idealist & 172 & 323.80 & & \\
\hline United Kingdom & Trust in the U.N. & Conservative Majority & 358 & 213.12 & $12,035.5$ & 0.010 \\
\hline & & Active Idealist & 82 & 252.73 & & \\
\hline Lithuania & Trust in country's parliament & Conservative Majority & 42 & 26.13 & 194.5 & 0.013 \\
\hline & & Active Idealist & 16 & 38.34 & & \\
\hline & Trust in the legal system & Conservative Majority & 42 & 26.58 & 213.5 & 0.032 \\
\hline & & Active Idealist & 16 & 37.16 & & \\
\hline & Trust in the U.N. & Conservative Majority & 42 & 26.70 & 218.5 & 0.039 \\
\hline & & Active Idealist & 16 & 36.84 & & \\
\hline Norway & Trust in country's parliament & Conservative Majority & 175 & 147.81 & $10,467.5$ & 0.019 \\
\hline & & Active Idealist & 141 & 171.76 & & \\
\hline & Trust in the legal system & Conservative Majority & 175 & 145.34 & $10,035.0$ & 0.004 \\
\hline & & Active Idealist & 141 & 174.83 & & \\
\hline & Trust in political parties & Conservative Majority & 175 & 147.97 & $10,494.0$ & 0.021 \\
\hline & & Active Idealist & 141 & 171.57 & & \\
\hline Sweden & Trust in country's parliament & Conservative Majority & 378 & 322.15 & $50,142.0$ & 0.000 \\
\hline & & Active Idealist & 322 & 383.78 & & \\
\hline
\end{tabular}


Table 5 (continued)

\begin{tabular}{lllllll}
\hline Country & Segments & N & Mean rank U & $\rho$ \\
\hline \multirow{2}{*}{ Trust in the legal system } & Conservative Majority & 378 & 332.71 & $54,135.0$ & 0.011 \\
& Active Idealist & 322 & 371.38 & & & \\
& Trust in political parties & Conservative Majority & 378 & 333.87 & $54,573.0$ & 0.017 \\
& Active Idealist & 322 & 370.02 & & & \\
& & & & & \\
\end{tabular}

Mann-Whitney tests, with the objective of comparing the mean ranks, were conducted for each of the 21 countries allowing an examination on how the identified clusters differed regarding trust in five social institutions. Considering that the countries of study have differentiated cultural, economic, and political backgrounds that could affect institutional trust, Mann-Whitney tests were performed on each country.

The results of the Mann-Whitney tests (Table 5) revealed that in about half of the studied countries (10 out of 21 countries) the boycott segments revealed significant differences regarding trust in public institutions. The countries were significant differences were found include Austria, Belgium, Germany, Denmark, Finland, France, United Kingdom, Lithuania, Norway and Sweden. On the contrary, we found no significant differences regarding trust in public institutions in Switzerland, Netherlands, Czech Republic, Spain, Hungary, Ireland, Israel, Poland and Portugal. The results of the Mann-Whitney tests also showed that in five countries (Belgium, France, Lithuania, Norway and Sweden) boycotters classified in the conservative majority and active idealist differ in their levels of trust in most public institutions.

Analyzing the mean ranks (Table 5) we can conclude that active idealists reveal a higher level of trust in public institutions than the conservative majority segment. The least differences between the groups concerned trust in the police and the United Nations and the higher differences between groups related to trust in country's parliament and trust in political parties. The exceptions occurred in the United Kingdom, were we found significant differences $(U=12,035.5 ; \rho=0.010)$ across the segments in their level of trust in the United Nations and in Belgium were we found significant differences ( $U=4784.0$; $\rho=0.003$ ) between the two segments in the level of trust they posit on the police.

\section{Conclusions}

This research aimed to present a model suitable for the segmentation of political consumers engaging in boycotting and to test the hypothesis of non-homogeneity of boycotters in relation to trust in several public institutions. In line with previous studies, we presented a model for the segmentation of boycotters including objective and inferred variables, which lead to a two-cluster solution.

The first and most populated segment, which we named conservative majority, is characterized by higher income, but lower education. Individuals belonging to this segment are least likely to belong to any organization and have less interest in politics. The most salient human value for this segment was conservadorism. 
The second cluster of boycotters, which we named active idealists, is composed of highly educated individuals, but with lower income. Members of this cluster tend to be politically idealists, being more likely to belong to political parties, action groups or other organizations and are more interested in politics. In terms of human values, the most characteristic is self-transcendence, followed by openness to change.

A country level analysis revealed that in around half of the countries studied the two boycotters' segments have differentiated levels of trust in public institutions. The results obtained lead us to consider both hypotheses to be validated, meaning that: i) consumers engaging in boycotting are not an homogeneous group in terms of demographics, their levels of generalized trust, social participation, interest in politics and human values and; ii) the segments of boycotters differ in their level of trust in public institutions in at least half of the countries studied.

Our study adds to existing knowledge by presenting a segmentation model of boycotters' and by relating these segments with differentiated levels of institutional trust. From a practical perspective, separating boycotting from buycotting can help managers to develop more effective strategies by responding to the unique processes and motivations associated with each form of political consumerism (Neilson 2010), thus understanding boycotters is considered an important issue for marketing strategies.

This research presents some limitations. First, we segmented the general sample of boycotters into a two-cluster solution. By doing so, we precluded the consideration of the specific characteristics of boycotters in each country, which implied different cluster solutions. We followed the methodology adopted in previous studies (Hong et al. 2012) that presents the advantages of facilitating the sequential comparison of the levels of institutional trust in each cluster in the various countries analyzed. However, we were not able to account for the characteristics of the segments in each individual country. Second, although the definition of the segmentation variables was supported on the literature, the selection of other variables could have determined different cluster solutions. It is possible that some relevant variables were missing from the model. Future studies could attend to these limitations by developing country specific segmentation models or including other variables in the cluster analysis.

Other possibilities of research that we find relevant include: i) research about the meaningful differences between boycotters from different regions, such as northernwestern and southern or former eastern European bloc countries or other regions of the world; ii) the study of the antecedents and motivations for each typology of boycotters identified; iii) research about public policies that, targeting boycotters, can foster institutional trust and iv) research focusing on the link between boycotting and other forms of unconventional political participation, such as buycotting, signing petitions, participating in protests and public demonstrations or membership in non-political organizations.

Funding R\&D Centre funded by the Multiannual Funding Programme of R\&D Centres of FCT Portuguese Foundation for Science and Technology, Ministry of Education and Science.

\section{Compliance with ethical standards}

Conflict of interest The authors declare that they have no conflict of interest. 


\section{References}

Acik, N. (2013). Reducing the participation gap in civic engagement: Political consumerism in Europe. European Sociological Review, 29(6), 1309-1322. https://doi.org/10.1093/esr/jct016

Aish, E. A., Mckechnie, S., Abosag, I., \& Hassan, S. (2013). The mystique of macro-boycotting behaviour: A conceptual framework. International Journal of Consumer Studies, 37(2), 165-171. https://doi.org/10.1111/j.1470-6431.2012.01108.x

Albrecht, C., Campbell, C., Heinrich, D., \& Lammel, M. (2013). Exploring why consumers engage in boycotts: Toward a unified model. Journal of Public Affairs, 13(2), 180-189.

Andersen, J., \& Tobiasen, M. (2004). Who are these political consumers anyway? Survey evidence. In Michele, M., Follesda, A. \& Stolle, D. (Ed.), Politics, products, and markets: exploring political consumerism past and present (pp. 203-221). New Brunswick.

Baek, Y. M. (2010). To buy or not to buy: Who are political consumers? What do they think and how do they participate? Political Studies, 58(5), 1065-1086. https://doi.org/10.1111/j.1467-9248.2010.00832.x

Bossy, S. (2014). The utopias of political consumerism: The search of alternatives to mass consumption. Journal of Consumer Culture, 14(2), 179-198. https://doi.org/10.1177/1469540514526238

Braunsberger, K., \& Buckler, B. (2011). What motivates consumers to participate in boycotts: Lessons from the ongoing Canadian seafood boycott. Journal of Business Research, 64(1), 96-102. https://doi.org/10.1016/j.jbusres.2009.12.008

Davidov, E. (2010). Testing for comparability of human values across countries and time with the third round of the European social survey. International Journal of Comparative Sociology, 51(3), 171-191. https://doi.org/10.1177/0020715210363534

De Barcellos, M. D., Teixeira, C. M., \& Venturini, J. C. (2014). Personal values associated with political consumption: An exploratory study with university students in Brazil. International Journal of Consumer Studies, 38(2), 207-216. https://doi.org/10.1111/ijcs.12084

ESS. (2014). Weighting European social survey data. Retrieved April 15, 2017, from https://www. europeansocialsurvey.org/methodology/ess_methodology/data_processing_archiving/weighting.html.

Ferrer-Fons, M., \& Fraile, M. (2014). Political consumerism and the decline of class politics in Western Europe. International Journal of Comparative Sociology, 54(5-6), 467-489. https://doi.org/10.1177 /0020715213516476

Friedman, M. (1985). Consumer boycotts in the United States, 1970-1980: Contemporary events in historical perspective. The Journal of Consumer Affairs, 19(1), 96-117.

George, D., \& Mallery, M. (2010). SPSS for windows Setp by step: A simple guide and reference, 7.0 update (10th ed.). Boston: Pearson.

Gotlieb, M. R., \& Wells, C. (2012). From concerned shopper to dutiful citizen: Implications of individual and collective orientations toward political consumerism. Annals of the American Academy of Political and Social Science, 644(1), 207-219.

Hoffmann, S., \& Müller, S. (2009). Consumer boycotts due to factory relocation. Journal of Business Research, 62(2), 239-247.

Hong, H., Park, H., Lee, Y., \& Park, J. (2012). Public segmentation and government-public relationship building: A cluster analysis of publics in the United States and 19 European countries. Journal of Public Relations Research, 24(1), 37-68. https://doi.org/10.1080/1062726X.2012.626135

IBM. (2011). Twostep cluster analysis. Retrieved April 15, 2017, from https://www.ibm. com/support/knowledgecenter/SSLVMB_20.0.0/com.ibm.spss.statistics.help/idh_twostep_main.htm.

Ki, E. J., \& Hon, L. C. (2007). Reliability and validity of organization-public relationship measurement and linkages among relationship indicators in a membership organization. Journalism \& Mass Communication Quarterly, 84(3), 419-438.

Koos, S. (2012). What drives political consumption in Europe? A multi-level analysis on individual characteristics, opportunity structures and globalization. Acta Sociologica, 55(1), 37-57. https://doi.org/10.1177 $/ 0001699311431594$

Neilson, L. (2010). Boycott or buycott? Understanding political consumerism. Journal of Consumer Behaviour, 9(3), 214-229. https://doi.org/10.1002/cb.313

Neilson, L., \& Paxton, P. (2010). Social capital and political consumerism: A multilevel analysis. Social Problems, 57(1), 5-24.

Norusis, M. J. (2008). SPSS 16.0 guide to data analysis (2nd ed.). Upper Saddlr River: Prentice Hall.

Robinson, O. C. (2013). Values and adult age: Findings from two cohorts of the European social survey. European Journal of Ageing, 10(1), 11-23. https://doi.org/10.1007/s10433-012-0247-3 
Schoene, M. (2016). Urban continent, urban activism? European cities and social movement activism. Global Society, 31(3), 1-22. https://doi.org/10.1080/13600826.2016.1203295

Schwartz, S. (1992). Universals in the content and structure of values: Theoretical advances and empirical tests in 20 countries. Advances in Experimental Psychology, 25, 1-65.

Schwartz, S. (1994). Are there universal aspects in the content and structure of values? Journal of Social Issues, 50(4), 19-45.

Stolle, D., \& Hooghe, M. (2004). An empirical exploration of new forms of participation. Uppsala: Sweden: European Consortium for Political Research Joint Sessions.

Stolle, D., Hooghe, M., \& Micheletti, M. (2005). Politics in the supermarket: Political consumerism as a form of political participation. International Political Science Review, 26(3), 245-269.

Verba, S., \& Nie, N. (1972). Participation in America. New York: Harper and Row.

Wicks, J. L., Morimoto, S. A., Maxwell, A., Schulte, S. R., \& Wicks, R. H. (2013). Youth political consumerism and the 2012 presidential election: What influences youth boycotting and Buycotting? American Behavioral Scientist, 58(5), 715-732. https://doi.org/10.1177/0002764213515993

Willis, M. M., \& Schor, J. B. (2012). Does changing a light bulb lead to changing the world? Political action and the conscious consumer. The Annals of the American Academy of Political and Social Science, 644(1), 160-190.

Yates, L. S. (2011). Critical consumption. Boycotting and buycotting in Europe. European Societies, 13(2), 191-217. https://doi.org/10.1080/14616696.2010.514352

Zhang, X. (2015). "Voting with dollars": A cross-polity and multilevel analysis of political consumerism. International Journal of Consumer Studies, 39(5), 422-436. https://doi.org/10.1111/ijcs.12181 